\title{
Remuneração dos Executivos e Desempenho em Empresas Brasileiras Familiares e Não Familiares
}

\author{
Executives Compensation and Performance in Family and Non-Family \\ Brazilian Companies
}

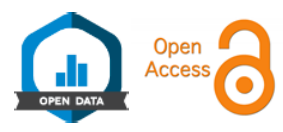
Ilse Maria Beuren ${ }^{1}$ Edgar Pamplona ${ }^{2}{ }^{\circ}$ Maurício Leite ${ }^{2 \oplus}$

\section{RESUMO}

Objetivo: com o intuito de produzir novos insights acerca dos efeitos da remuneração dos executivos nas empresas, investiga-se a relação da remuneração dos executivos com o desempenho (curto prazo) e a política de investimentos (longo prazo) em empresas brasileiras familiares e não familiares listadas na Brasil, Bolsa, Balcão (B3). Métodos: pesquisa de procedimento documental foi realizada com dados da Economática ${ }^{\circledR}$ e de relatórios das empresas (Relatório da Administração, Formulário de Referência e Notas Explicativas). A amostra de 87 empresas compõe-se de 48 familiares e 39 não familiares. Resultados: indicam que a remuneração variável de curto prazo apresenta relação com desempenho e política de investimentos das empresas, enquanto a remuneração variável de longo prazo não apresentou significância. A remuneração variável de curto prazo revela potencial para maximizar o desempenho das empresas, com impacto mais forte nas não familiares. Em face à política de investimentos, a remuneração variável de curto prazo apresenta relação negativa, mas este efeito é revertido para as empresas não familiares. Conclusão: a remuneração dos executivos pode ser um mecanismo de governança para alinhar os interesses das partes, tanto em empresas familiares como em não familiares. Todavia, seu dimensionamento preciso deve considerar o tipo de propriedade e gestão corporativa.

Palavras-chave: remuneração dos executivos; desempenho; política de investimentos; empresas familiares; empresas não familiares.

Classificação JEL: M12, M52, L25, M41

'Universidade Federal de Santa Catarina, Departamento de Ciências Contábeis, Florianópolis, SC, Brasil.

${ }^{2}$ Universidade Regional de Blumenau, Programa de Pós-Graduação em Ciências Contábeis, Blumenau, SC, Brasil.

Como citar: Beuren, I. M., Pamplona, E., \& Leite, M. (2020). Executives compensation and performance in family and non-family Brazilian companies. Revista de Administração Contemporânea, 24(6), 514-531. https://doi.org/10.1590/1982-7849rac2020190191

\# de revisores convidados até a decisão:

\begin{tabular}{|c|c|c|c|c|c|c|c|c|c|}
\hline & 1 & 2 & 3 & 4 & 5 & 6 & 7 & 8 & 9 \\
\hline $1^{a}$ rodada & (x) & $\stackrel{9}{2}$ & (x) & $\stackrel{\infty}{2}$ & (x) & & & & \\
\hline $2^{a}$ rodada & 2 & 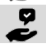 & & & & & & & \\
\hline $3^{a}$ rodada & $\stackrel{9}{=}$ & & & & & & & & \\
\hline
\end{tabular}

Objective: in order to produce new insights for the knowledge about the effects of executive compensation on companies, relationship between performance (short-term) and investment policy (long-term) in Brazilian family and non-family companies listed in Brazil, Bolsa, Balcão (B3) are investigated. Methods: documentary procedure research was conducted with data from Economática ${ }^{\circledR}$ and company reports (Management Report, Reference Form and Explanatory Notes). The sample of 87 companies consists of 48 family and 39 non-family companies. Results: indicate that the short-term variable remuneration is related to the performance and investment policy of the companies, while the long-term variable remuneration was not significant. Short-term variable compensation reveals potential to maximize corporate performance, with a stronger impact on non-family companies. In view of the investment policy, short-term variable compensation presents a negative relation, but this effect is reverted to non-family companies. Conclusion: executive compensation can be a governance mechanism to align the interests of the parties, both in family and non-family companies. However, its precise dimensioning must consider the type of ownership and corporate management.

Keywords: executive compensation; performance; investment policy; family companies; non-family companies. 


\section{INTRODUÇÃO}

A Teoria da Agência postula que as partes de uma organização possuem interesses próprios, ocorrendo conflitos quando não há esforços cooperativos. Esta cooperação não inclui apenas parcerias, mas muitas vezes interações familiares, que tornam o fenômeno ainda mais complexo. Como os conflitos de interesses causam problemas, temse a compensação executiva como um mecanismo de controle para alcançar o alinhamento dos interesses entre acionistas e executivos (Aggarwal \& Ghosh, 2015). Independentemente de como é dimensionada, o propósito é vincular os interesses para maximizar o desempenho.

Os efeitos da remuneração dos executivos no desempenho das empresas têm sido um tema controverso nas comunidades acadêmica e empresarial, chamando atenção inclusive da mídia e do público em geral (Liang, Moroney, \& Rankin, 2018). McConaughy (2000) destaca que esforços têm sido empreendidos na investigação da sensibilidade da remuneração dos executivos ao desempenho da empresa e fatores que afetam tal sensibilidade. Outro aspecto pesquisado é que executivos remunerados pelo desempenho oferecem incentivos para melhorar a performance empresarial. Esta temática também é de interesse dos acionistas que vislumbram a maximização do retorno do capital investido.

Nessa perspectiva, o desenho de um pacote de remuneração atrativo e compatível com a realidade do mercado, que apresente incentivos tanto de curto quanto de longo prazo e com metas claras de desempenho, é benéfico para a manutenção das relações entre acionistas e executivos (Silva \& Chien, 2013). O que torna o fenômeno a ser observado ainda mais complexo é que os pacotes de compensação das empresas podem ser representados por inúmeros elementos, como salário-base, bônus anual, ações e opções de ações, seguros, benefícios de pensão e indenização (Georgen \& Renneboog, 2011).

Embora haja amplas evidências teóricoempíricas de que os executivos respondem aos programas de compensação, ainda não há consenso quanto ao entendimento de que o aumento dos incentivos dos executivos leve a decisões de interesse dos acionistas. Executivos, ao entenderem como suas ações afetam os lucros contábeis, podem tender a concentrar-se em projetos que aumentem os bônus contábeis e dedicar menos atenção aos preços das ações, que, consequentemente, afetam o valor da empresa para o acionista (Murphy, 1999).

Esta discussão ganhou maior ênfase no Brasil a partir da instrução normativa n. $^{0} 480$ da Comissão de Valores Mobiliários (CVM), de 7 de dezembro de 2009, que versa sobre a obrigatoriedade de as empresas de capital aberto apresentarem de forma detalhada as informações sobre a remuneração dos executivos (Beuren, Silva, \& Mazzioni, 2014; Machado \& Beuren, 2015). Apesar da obrigatoriedade de divulgação das informações sobre a remuneração dos principais executivos, Silva e Chien (2013) argumentam que tal informação é ainda insatisfatória, visto que diversas empresas não apresentam o detalhamento adequado e outras simplesmente não disponibilizam as informações exigidas.

Os problemas de agência em empresas, sejam elas familiares, sejam não familiares, influenciam os pesos relativos dos indicadores de desempenho (ex post) e de orientação estratégica (ex ante) sobre a remuneração dos executivos (Tsao, Lin, \& Chen, 2015). Todavia, Cheng (2014) destaca que as empresas familiares comparativamente às suas contrapartes não familiares apresentam características diferenciadas, tais como: visão temporal superior, o que implica a preocupação com o valor de longo prazo em detrimento dos ganhos de curto prazo; e preferências peculiares nas decisões das empresas, visto que os membros da família estão envolvidos ativamente na gestão, o que torna imprescindível seu estudo de forma individual.

Diante do exposto, apresenta-se a questão que norteia este estudo: qual a relação da remuneração dos executivos com o desempenho (curto prazo) e a política de investimentos (longo prazo) em empresas brasileiras familiares e não familiares? Nesse sentido, este estudo objetiva investigar a relação da remuneração dos executivos com o desempenho (curto prazo) e a política de investimentos (longo prazo) em empresas brasileiras familiares e não familiares listadas na Brasil, Bolsa, Balcão (B3). O período temporal de estudo compreende os anos de 2012 a 2017, últimos seis anos quando da realização da pesquisa.

Este estudo justifica-se pelas contribuições teóricas e práticas. Do ponto de vista teórico, tem como propósito a consolidação das relações já identificadas nos países desenvolvidos entre a remuneração variável e o desempenho e entre a remuneração variável e os investimentos. Com isso, será possível elucidar se o conhecimento produzido até então se aplica também ao contexto de países em desenvolvimento. Pesquisas dessa natureza são essenciais para validações da teoria existente ou de novas ramificações teóricas para contextos emergentes, como o caso brasileiro.

$\mathrm{Na}$ perspectiva prática, espera-se contribuir com o fortalecimento dos mecanismos de governança corporativa, dado que o correto 
dimensionamento da remuneração variável, que visa ao alinhamento de interesses entre acionistas e gestores, tem potencial para proporcionar às empresas a maximização de seu desempenho presente e a eficiente alocação de recursos, visando a um futuro perene para a corporação. Como contribuição adicional, busca-se de forma indireta a consecução de uma sociedade mais bem desenvolvida, visto a inserção das empresas na qualidade de vida dos indivíduos.

\section{FUNDAMENTAÇÃO TEÓRICA}

\section{Remuneração dos executivos}

Durante a década de 1980 e início da seguinte, têm sido enfatizados de forma abrangente os altos prêmios de remuneração ofertados aos diretores de empresas (Gregg, Machin, \& Szymanski, 1993). Lee (2009) destaca que a questão da remuneração dos executivos tem atraído a atenção de acadêmicos e da mídia. Aggarwal e Ghosh (2015) mencionam que tem havido alta especulação e interesse com a remuneração dos chief executive officers (CEOs). Esta discussão perpassa os preceitos da teoria financeira convencional, sugerindo que os gestores devem aceitar apenas projetos que aumentem o valor da empresa, mas, na prática, podem ter incentivos para se afastar dessa política (Eisdorfer, Giaccotto, \& White, 2013).

Georgen e Renneboog (2011) mencionam que existem duas visões contrastantes na literatura acerca de compensações. Por um lado, a compensação dos gestores é vista como resultado de um mecanismo baseado no mercado, garantindo que os executivos tenham incentivos adequados a fim de maximizar o valor para o acionista. Por outro lado, é considerada um meio pelo qual os executivos expropriam os acionistas, tendendo a se beneficiar de ganhos inesperados. Logo, o nível e o mix de remuneração são meios importantes para incentivar os executivos a alinhar seus interesses com os dos acionistas.

Os pacotes de compensação das empresas podem consistir no todo ou em parte dos seguintes componentes: salário-base, bônus anual, ações e opções de ações, seguros, benefícios de pensão e indenização (Georgen \& Renneboog, 2011). Tais formas de remuneração do CEO são mecanismos utilizados pelos conselheiros para alinhar os interesses dos acionistas e gestores (Combs, Penney, Crook, \& Short, 2010). A remuneração baseada em ações, por exemplo, deve alinhar os interesses dos executivos e os dos acionistas, vinculando a remuneração aos aumentos no valor de mercado da empresa (Abowd \& Kaplan, 1999).
Murphy (1999) já alertava que os executivos dedicam atenção substancial ao processo de determinação de salário. Decorre que o saláriobase é um componente-chave do contrato de trabalho, que garante aumentos mínimos ao longo do tempo. Uma vez que o salário-base representa o componente fixo em contratos, os executivos avessos ao risco irão preferir, naturalmente, um aumento no salário-base em detrimento de um aumento equivalente do bônus-alvo e/ou remuneração variável. Acerca do bônus anual, destaca que praticamente todas as empresas com fins lucrativos aprovam um plano com este tipo de remuneração para seus executivos, sendo este pago anualmente com base no desempenho do período.

Em outra dimensão da compensação dos executivos, Georgen e Renneboog (2011) dividem a remuneração corporativa em remuneração de curto prazo e de longo prazo. A compensação de curto prazo inclui o salário-base e qualquer plano de bônus baseado no desempenho. Já os componentes de remuneração de longo prazo incluem elementos como opções de compra de ações. Em alguns casos, as empresas oferecem aos seus gestores planos suplementares de aposentadoria executiva e pagamento de indenizações.

De acordo com Duffhues e Kabir (2008), a literatura preconiza que a remuneração dos executivos deve se refletir no desempenho organizacional, sendo observados inúmeros estudos que utilizam medidas diversas de performance em todo o mundo. Logo, diante da importância deste tema, abordam-se, na sequência, os arranjos observados em pesquisas teóricoempíricas acerca da remuneração dos executivos no desempenho organizacional.

\section{Relação da remuneração no desempenho organizacional}

De acordo com Jensen e Meckling (1976), os agentes (gestores) nem sempre desempenham suas atividades no interesse do principal (acionistas). Neste sentido, mecanismos são adotados pelas empresas para motivar os executivos a desempenhar suas funções, sendo um deles o de incentivos (Duffhues \& Kabir, 2008). Este tem o propósito de motivá-los a desempenhar suas funções de forma mais acurada, contribuindo para o aumento do desempenho organizacional. Assim, é esperado que haja relação positiva entre a remuneração dos executivos e o desempenho organizacional (Duffhues \& Kabir, 2008).

Kato e Kubo (2006) averiguaram a compensação do CEO e o desempenho de empresas no contexto japonês. Os resultados apontaram que, consistentemente, a remuneração em 
dinheiro do CEO é sensível ao desempenho da empresa, especialmente às medidas contábeis. Wet (2012) examinou a relação entre remuneração dos executivos das empresas cotadas na Johannesburg Securities Exchange (JSE) da África do Sul e indicadores de desempenho tradicionais e contemporâneos. Os resultados fornecem evidências de que existe relação positiva entre a remuneração dos executivos e as medidas de desempenho financeiro.

É essencial observar que, embora a Teoria da Agência tenha sido a força dominante no cerne dos esforços para vincular a remuneração dos executivos ao desempenho, alguns pesquisadores questionam a validade desta visão (Wet, 2012). Kuo, Lin, Lien, Wang e Yeh (2014) advertem que a evidência empírica existente sobre a relação da remuneração por desempenho não suporta evidência robusta. Por um lado, estudos encontraram relação positiva e significativa entre remuneração e desempenho, enquanto outros relatam haver influência negativa ou não significativa entre estas variáveis.

Por exemplo, Duffhues e Kabir (2008) analisaram a relação entre remuneração dos executivos e desempenho das empresas listadas na Euronext Amsterdam da Holanda. Os resultados não apontaram relação entre remuneração e desempenho. Desta forma, questionam o conhecimento convencional de que a remuneração dos executivos auxilia no alinhamento dos interesses dos acionistas com os dos executivos.

Nestecontexto, umadaslacunas écompreender quais são os impactos da compensação de curto e longo prazo em indicadores de desempenho. Para tanto, Alregab (2015) testou a relação de diferentes formas de remuneração em medidas de desempenho de empresas do Reino Unido. Temse que os bônus dos CEOs (remuneração variável de curto prazo) estão positivamente associados a medidas de desempenho de curto prazo, apesar de terem impacto negativo no retorno total dos acionistas. Já a compensação variável de longo prazo tem impacto positivo no desempenho com perspectiva temporal similar.

Com base nas argumentações expostas, sobretudo nas de Alregab (2015), busca-se identificar relação entre a remuneração variável de curto prazo e de longo prazo dos executivos no desempenho de empresas brasileiras familiares e não familiares. Desta forma, formula-se a seguinte hipótese de pesquisa:

$\mathbf{H}_{1}$ : Existe relação positiva entre a remuneração dos executivos e o desempenho de empresas brasileiras, sendo esta diferente para empresas não familiares comparativamente a suas contrapartes familiares.
$\mathbf{H}_{1 \mathrm{a}}$ : Existe relação positiva entre a remuneração variável de curto prazo dos executivos e o desempenho de empresas brasileiras, sendo esta diferente para empresas não familiares comparativamente a suas contrapartes familiares.

$\mathbf{H}_{1 \mathrm{~b}}$ : Existe relação positiva entre a remuneração variável de longo prazo dos executivos e o desempenho de empresas brasileiras, sendo esta diferente para empresas não familiares comparativamente a suas contrapartes familiares.

Cabe destacar que a relação positiva esperada entre a remuneração dos executivos e o desempenho de empresas brasileiras está vinculada à crença generalizada de que a remuneração dos executivos deve refletir no desempenho da empresa (Duffhues \& Kabir, 2008) de forma positiva, visto que alinha os interesses dos acionistas com os dos gestores. Tal hipótese é observada em estudos desenvolvidos em todo o mundo, como o de Wet (2012) no contexto sul-africano e o de Subekti e Sumargo (2015) no cenário indonésio.

A diferenciação na magnitude da relação para empresas familiares e não familiares decorre da visão de horizonte existente. De acordo com Anderson e Reeb (2003), as famílias possuem horizontes temporais superiores, o que induz a investimentos de projetos de longo prazo. Como as empresas familiares são potencialmente defensoras da maximização do valor para períodos futuros (Anderson \& Reeb, 2003), e as medidas de desempenho utilizadas nesta pesquisa focam no curto prazo, espera-se que maior remuneração dos executivos influencie de forma mais intensa o desempenho de empresas não familiares, visto que tais gestores focalizam projetos que trazem retorno mais imediato.

No cenário brasileiro, Silva, Souza e Klann (2016) defendem que as empresas familiares não possuem foco tão centrado no lucro imediato quanto as empresas não familiares. Goes, Martins e Machado Filho (2017) observaram que as empresas brasileiras de capital aberto, com algum tipo de relação familiar, tendem a auferir lucro líquido inferior a suas contrapartes não familiares. Santos e Silva (2018) identificaram que os executivos de empresas familiares brasileiras obtêm remuneração, incluindo do tipo variável, inferior à das empresas não familiares. Depreende-se do exposto que as empresas familiares apresentam visão de longo prazo e desempenho inferior e, ainda, que os executivos têm incentivos menores para gerar resultados de curto prazo, fazendo com que os impactos da remuneração variável de curto e de longo prazo nas empresas não familiares sejam maiores, conforme previsto na hipótese. 
Relação da remuneração na política de investimentos

Impulsionado pela concepção de que muitas corporações em todo o mundo são comandadas pelos fundadores das empresas e suas famílias, vários estudos se concentraram na influência das famílias nas decisões de investimentos (Kim, Kim \& Lee, 2008; Schmid, Achleitner, Ampenberger, \& Kaserer, 2014). Embora os mecanismos de controle orientados aos acionistas estejam intrinsecamente relacionados ao desempenho, eles nem sempre estão relacionados aos planos de investimentos (Yoo \& Sung, 2015). A despeito disso, Chen, Chen e Yang (2017) apontam que, devido ao risco inerente e suas características de longo prazo, as empresas fornecem incentivos aos gestores como forma de motivação, alinhando seus próprios interesses com os planos de investimentos da organização.

Gibbons e Murphy (1992) aduzem que os altos executivos desempenham papel importante na concepção de políticas de investimentos de longo prazo. A disposição deles em realizar investimentos depende de vários fatores, incluindo os potenciais benefícios financeiros e não financeiros que recebem. Neste contexto, por definição, tais decisões de investimento implicam negociação de despesas correntes contra receitas futuras. Logo, se as receitas se estenderem para o futuro, os executivos responsáveis pela política de investimentos de longo prazo podem não estar mais no cargo quando as receitas forem realizadas.

Nesta perspectiva, é de se esperar que quanto maior a remuneração dos executivos, principalmente variável e vinculada às medidas de curto prazo (que são significativas sobre o todo), menor será a propensão à realização de investimentos em ativos fixos e P\&D, visto que a alocação de recursos dar-se-á antes do retorno, minimizando a compensação dos executivos no período atual. Gong (2011) enfatiza que executivos preferem investir em projetos de curto prazo que produzam maiores retornos em períodos reduzidos, gerando assim uma percepção de maior capacidade e, por consequência, alavancando a obtenção de maior remuneração.

Com base no exposto, presume-se haver relação negativa entre a remuneração dos executivos - pela perspectiva de remuneração variável de curto prazo e de longo prazo - e a política de investimentos de empresas familiares e não familiares brasileiras. Assim, formula-se a segunda hipótese da pesquisa:

$\mathbf{H}_{2}$ : Existe relação negativa entre a remuneração dos executivos e a política de investimentos de empresas brasileiras, sendo esta diferente para empresas não familiares comparativamente a suas contrapartes familiares.

$\mathbf{H}_{2 \mathrm{a}}$ : Existe relação negativa entre a remuneração variável de curto prazo dos executivos e a política de investimentos de empresas brasileiras, sendo esta diferente para empresas não familiares comparativamente a suas contrapartes familiares.

$\mathbf{H}_{2 \mathrm{~b}}$ : Existe relação negativa entre a remuneração variável de longo prazo dos executivos e a política de investimentos de empresas brasileiras, sendo esta diferente para empresas não familiares comparativamente a suas contrapartes familiares.

A presunção de relação negativa entre remuneração dos executivos e política de investimentos, mensurada pelas aquisições de ativos fixos e investimentos em P\&D, está pautada na perspectiva temporal de interesse dos executivos, que irão preterir investimentos de longo prazo com o intuito de alocar os recursos disponíveis em projetos de curto prazo, visando a maximizar os resultados atuais e, por consequência, a sua remuneração. Quanto à intensidade da relação, espera-se que a influência negativa da remuneração dos executivos na política de investimentos seja diferente para empresas não familiares em comparação às contrapartes familiares. Tal aspecto é suportado na literatura, como por Yoo e Sung (2015), que apoiam os argumentos de que empresas familiares despendem mais recursos em P\&D.

Tsao, Lin e Chen (2015) sustentam que empresas familiares, entendendo a importância dos investimentos para o crescimento e a sua sobrevivência, tendem a focar seus planos no longo prazo de forma mais intensa comparativamente às empresas não familiares. A literatura sugere que, devido ao seu horizonte temporal de longo prazo e seu alinhamento com a concentração de propriedade, é de se esperar que as empresas familiares tendam a uma maior intensidade nos investimentos em P\&D. Depreende-se das pesquisas de Yoo e Sung (2015) e de Tsao et al. (2015) uma relação negativa entre remuneração dos executivos e política de investimentos, e tal relação deve ser diferente em empresas familiares e não familiares.

No cenário brasileiro, Flores Júnior e Grisci (2012) defendem que nas empresas familiares está enraizada a expectativa de perpetuidade, o que ultrapassa o ambiente empresarial ao considerar conjuntamente o seio familiar, ou seja, o orgulho e a preservação do nome da família na sociedade. De acordo com Flores e Grisci (2012), a mistura familiar abrange relações familiares, sociedade patrimonial e trabalho em conjunto. Portanto, espera-se que 
as empresas familiares possuam incentivos mais nobres do que suas contrapartes não familiares, carregando-as para deixar um legado à sociedade, que pode ser representado por investimentos mais abundantes, conforme previsto na hipótese.

\section{PROCEDIMENTOS METODOLÓGICOS}

Pesquisa documental foi realizada, tendo-se como população as empresas brasileiras familiares e não familiares listadas na Brasil, Bolsa, Balcão (B3), ativas no ano de 2018. O período de análise abrangeu seis anos, sendo de 2012 a 2017. Este recorte temporal foi realizado por duas razões principais: (a) pesquisas anteriores acerca do tema, como de Duffhues e Kabir (2008) e Wet (2012), utilizaram lacunas temporais similares, sugerindo ser um parâmetro confiável para o fenômeno investigado; e (b) visto que foram utilizados dados balanceados na pesquisa, o recorte temporal maior reduziria consideravelmente o número de empresas na amostra, limitando a operacionalização do estudo.

Para a composição da amostra, excluíramse: as empresas do segmento financeiro, por apresentarem características específicas; as que apresentaram patrimônio líquido negativo, porque impactaria na composição do índice de rentabilidade; e aquelas sem informações disponíveis para o cálculo das variáveis ao longo de todo o período estudado (2012 a 2017). Excluíram-se, ainda, as empresas classificadas como outliers, por estarem dois desvios-padrão distantes da média geral. A exclusão de outliers foi efetuada para todas as variáveis do tipo numérico da pesquisa. Os valores atípicos ou extremos (outliers) podem distorcer os resultados, levando o pesquisador a conclusões equivocadas; por isso, foram retirados. Assim, a amostra final foi composta por 87 empresas que geraram 522 observações.

Na sequência, a amostra de pesquisa foi subdividida em dois grupos, sendo empresas familiares e não familiares. Para classificar uma empresa como familiar adotaram-se os seguintes critérios: membros da família que detêm 20\% ou mais (por intermédio de pessoas físicas) das ações da companhia (La Porta, Lopez-de-Silanes, \& Shleifer, 1999); e/ou com dois ou mais membros da família participando da administração dos negócios (Anderson \& Reeb, 2003). No Brasil, Goes et al. (2017) utilizaram em sua pesquisa os mesmos critérios, fornecendo suporte à classificação adotada nesta pesquisa.

Para identificar estas informações foi consultado o formulário de referência das empresas, disponível no site da B3. A participação da família no capital foi averiguada no item 15 - Controle e Grupo Econômico, no subitem 15.1/2 - Posição Acionária. A participação familiar no Conselho de Administração das empresas foi capturada no item 12 - Assembleia e Administração, nos subitens 12.5/6 - Composição e Experiência Profissional da Administração e do Conselho Fiscal e 12.9 Relações Familiares. Na amostra de empresas, 48 $(55,2 \%)$ foram classificadas como familiares e 39 $(44,8 \%)$ como não familiares.

$\mathrm{Na}$ classificação realizada, deve-se ressalvar dois aspectos. No Brasil, as organizações negociam ações ordinárias e ações preferenciais, sendo que estas últimas não dão direito a voto em assembleia, ou seja, não configuram potencial de controle corporativo. Como neste estudo se observou a composição do capital total das empresas, algumas variações de ordem de controle podem ocorrer. Todavia, dado que as ações preferenciais são exigíveis, tendo a empresa o direito de recomprálas dos acionistas, geralmente são adquiridas por investidores minoritários, pessoas físicas, que possuem uma parcela ínfima do total da empresa. Desse modo é esperado que, no mercado acionário brasileiro, se uma família detém $20 \%$ ou mais das ações totais da companhia, essa proporção seja mantida, ou até elevada, se consideradas apenas as ações ordinárias, que dão direito a voto em assembleia. Ressalta-se que grandes acionistas tendem a possuir ações ordinárias, para assegurar o controle e a gestão corporativa.

Outro aspecto classificatório a ressalvar é a participação de holdings nas empresas analisadas. Por ter sido observada a composição de $20 \%$ ou mais das ações das companhias com exclusividade ao capital de pessoas físicas, não se pode afirmar que a pessoa jurídica (holding) detentora de capital da empresa em análise é familiar ou não. Para mitigar tal aspecto, foi considerada, além da propriedade, a administração corporativa. Presume-se que uma holding administrada por uma família, quando controladora de outra empresa, colocará membros da sua família na gestão de sua controlada. Portanto, tal limitação é mitigada na consideração conjunta de propriedade e gestão para a classificação de empresas familiares.

As variáveis utilizadas no construto da pesquisa, que, conforme a literatura revisitada, podem apresentar potencial relação entre remuneração dos executivos e desempenho (curto prazo) e política de investimentos (longo prazo) de empresas, são apresentadas na Tabela 1 . 
Tabela 1. Construto com as variáveis dependentes, independentes e de controle.

\begin{tabular}{|c|c|c|c|c|}
\hline & Variável & Fórmula & Autores & Fonte \\
\hline \multicolumn{5}{|c|}{ Variáveis dependentes } \\
\hline \multirow{2}{*}{ 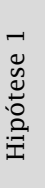 } & $\begin{array}{c}\text { Retorno sobre os ativos } \\
\text { (ROA) }\end{array}$ & $\frac{\text { EBIT }}{\text { Ativo total }}$ & $\begin{array}{l}\text { Duffhues e Labor (2008); Tsao et al. } \\
\qquad(2015)\end{array}$ & Economática $^{\circledR}$ \\
\hline & $\begin{array}{l}\text { Retorno sobre o patrimônio } \\
\text { líquido (ROE) }\end{array}$ & $\frac{\text { Lucro líquido }}{\text { Patrimônio líquido }}$ & $\begin{array}{l}\text { Wet (2012); Kuo et al. (2014); Cheng } \\
\text { (2014) }\end{array}$ & Economática ${ }^{\circledR}$ \\
\hline \multirow{2}{*}{ 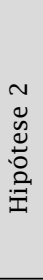 } & $\begin{array}{c}\text { Pesquisa e } \\
\text { desenvolvimento (P\&D) }\end{array}$ & $\begin{array}{l}\begin{array}{l}\text { Investimentos em } \\
\text { pesquisa e desenvolvimento }\end{array} \\
\text { Ativo total }\end{array}$ & $\begin{array}{l}\text { Kim et al. (2008); Tsao et al. (2015); } \\
\text { Chen et al. (2017) }\end{array}$ & $\begin{array}{l}\text { Notas explicativas, } \\
\text { relatório da } \\
\text { administração ou } \\
\text { formulário de referência }\end{array}$ \\
\hline & $\begin{array}{l}\text { Crescimento do ativo fixo } \\
\text { (CAF) }\end{array}$ & $\begin{array}{l}\text { Ativo imobilizado }{ }_{t}- \\
\text { Ativo imobilizado }{ }_{t-1}+ \\
\text { Depreciaçãot } \\
\text { Ativo imobilizado } o_{t-1}\end{array}$ & $\begin{array}{l}\text { Proposição diferenciada de } \\
\text { mensuração }\end{array}$ & Economática ${ }^{\circledR}$ \\
\hline
\end{tabular}

Remuneração variável de curto prazo (RVCP)

$\begin{gathered}\text { Remuneração variável } \\ \text { de curto prazo }\end{gathered}$
$\begin{gathered}\text { Demuneração total } \\ \text { de curto prazo (D_RVCP) }\end{gathered}$
onde Dummy

Remuneração variável de longo prazo (RVLP)

Dummy de remuneração variável de longo prazo (D_RVLP)
Remuneração variável

de longo prazo

Remuneração total
Remuneração variável

$\frac{\text { de longo prazo }}{\text { Remuneração total }} *$ Dummy
Formulário de referência

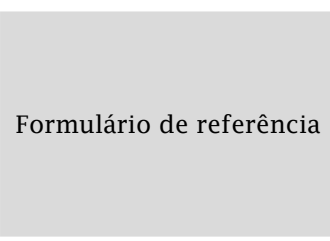

Proposição diferenciada de mensuração

Formulário de referência

onde Dummy =

0 se empresa familiar; e

1 se empresa não familiar

Variáveis de controle - Específicas da empresa

\begin{tabular}{lcc}
\hline Tamanho (TAM) & Kuo, Lien, Lien e Yeh (2014); \\
(2015) & Subekti e Sumargo (2015); Alregab & Economática ${ }^{\circledR}$
\end{tabular}

Idade (ID)

Folga financeira (FF)

Crescimento das vendas (CV)

Estrutura de capital (EC)
Número de anos de existência da empresa
Yoo e Sung (2015); Goes et al. (2017)

Formulário de referência

Formulário de referência

Kim et al. (2008)

Economática ${ }^{\circledR}$

$\frac{\text { Ativo circulante }}{\text { Passivo circulante }}$

Receita líq. vendas $s_{t}$

Receita líq.vendas $s_{t-1}$

Receita líq. vendas $s_{t-1}$

Kato e Kubo (2006)

Economática ${ }^{\circledR}$

Passivo circulante +

Passivo não circulante Ativo total

Duffhues e Kabir (2008); Cheng
(2014); Subekti e Sumargo (2015)
Economática ${ }^{\circledR}$

Variáveis de controle - Efeitos fixos

\begin{tabular}{|c|c|c|c|}
\hline Efeito fixo de setor & $\begin{array}{l}\text { Classificação Bovespa, tendo-se: } 1 \text {. Bens } \\
\text { industriais; } 2 \text {. Consumo cíclico; } 3 \text {. Consumo não } \\
\text { cíclico; } 4 \text {. Materiais básicos; } 5 \text {. Petróleo, gás e } \\
\text { biocombustíveis; } 6 \text {. Saúde; } 7 \text {. Telecomunicações; } \\
\text { e } 8 \text {. Utilidade pública. }\end{array}$ & - & Economática ${ }^{\circledR}$ \\
\hline Efeito fixo de ano & Período de estudo, tendo-se: 2012 a 2017 & - & Economática ${ }^{\circledR}$ \\
\hline
\end{tabular}

Nota. A remuneração variável de curto prazo é composta pelo somatório dos bônus, participação nos resultados, participação em reuniões, comissões e outros. A remuneração variável de longo prazo, por sua vez, é composta pelos numerários de pós-emprego, cessão e ações. A composição da remuneração total abrange, além da remuneração variável de curto prazo e da remuneração variável de longo prazo, a remuneração fixa. A remuneração fixa é composta por salários, benefícios, participação em comitês e outros. Fonte: Dados da pesquisa. 
Destaca-se que a composição das variáveis RVCP e RVLP, descritas em nota na Tabela 1, são aderentes ao formulário de referência das organizações, que seguem, por padrão, as exigências determinadas pela CVM, conforme instrução CVM n. ${ }^{\circ} 480$, de 7 de dezembro de 2009, em seu item 13.2, letra d. Portanto, para tal dimensionamento foram respeitados exclusivamente os parâmetros legais.
Ainda em consonância com as informações da Tabela 1, formularam-se equações de regressão linear múltipla, sendo que: as equações 1 e 2 estão vinculadas à hipótese $\mathrm{H}_{1 \mathrm{a}}$; as equações 3 e 4 estão vinculadas à hipótese $\mathrm{H}_{1 \mathrm{~b}}$; as equações 5 e 6 estão vinculadas à hipótese $\mathrm{H}_{2 \mathrm{a}}$; e as equações 7 e 8 estão vinculadas à hipótese $\mathrm{H}_{2 \mathrm{~b}}$. Tais equações contemplam suas respectivas variáveis dependentes, independentes e de controle, a saber:

$$
\begin{aligned}
& \mathrm{ROA}=\beta_{0}+\beta_{1} \mathrm{RVCP}_{\mathrm{it}}+\beta_{2} \mathrm{D}_{-} \mathrm{RVCP}_{\mathrm{it}}+\beta_{3} \mathrm{TAM}_{\mathrm{it}}+\beta_{4} \mathrm{ID}_{\mathrm{it}}+\beta_{5} \mathrm{FF}_{\mathrm{it}}+\beta_{6} \mathrm{CV}_{\mathrm{it}}+\beta_{7} \mathrm{EC}_{\mathrm{it}}+\Sigma \text { EfeitoFixoSetor }+\Sigma \text { EfeitoFixoAno }+\varepsilon \\
& \mathrm{ROE}=\beta_{0}+\beta_{1} \mathrm{RVCP}_{\mathrm{it}}+\beta_{2} \mathrm{D}_{-} \mathrm{RVCP}_{\mathrm{it}}+\beta_{3} \mathrm{TAM}_{\mathrm{it}}+\beta_{4} \mathrm{ID}_{\mathrm{it}}+\beta_{5} \mathrm{FF}_{\mathrm{it}}+\beta_{6} \mathrm{CV}_{\mathrm{it}}+\beta_{7} \mathrm{EC}_{\mathrm{it}}+\Sigma \text { EfeitoFixoSetor }+\Sigma \text { EfeitoFixoAno }+\varepsilon \\
& \mathrm{ROA}=\beta_{0}+\beta_{1} \mathrm{RVLP}_{\mathrm{it}}+\beta_{2} \mathrm{D}_{-} \mathrm{RVLP} \\
& \mathrm{it}
\end{aligned}
$$

Na análise dos dados, utilizaram-se planilhas eletrônicas, para fins de tabulação dos dados e estatísticas descritivas, bem como o software STATA $12^{\circledR}$, para análise das regressões. Inicialmente, efetuaram-se as estatísticas descritivas das variáveis, além dos testes de médias (t de Student) para verificar a existência de diferenças de médias entre os dois grupos investigados (empresas familiares e não familiares). Posteriormente, foram operacionalizados os modelos de regressão linear múltipla com controle fixo de setor e ano, com vistas no objetivo proposto. Por fim, para os modelos de regressão foram observados seus pressupostos: normalidade, multicolinearidade, autocorrelação dos resíduos e heterocedasticidade.

\section{DESCRIÇÃO E ANÁLISE DOS RESULTADOS}

\section{Análise descritiva e testes de médias}

$\mathrm{Na}$ Tabela 2 apresenta-se a estatística descritiva das variáveis numéricas dependentes
(ROA, ROE, P\&D e CAF), independentes (RVCP e RVLP) e de controle específicas da empresa (TAM, ID, FF, CV e EC).

Conforme a Tabela 2, relevante parcela das variáveis apresentou diferenças significativas de médias entre empresas familiares e não familiares. Quanto às dimensões de desempenho, tanto o ROA quanto o ROE são maiores em empresas não familiares comparativamente às empresas familiares. Tal resultado pode ser compreendido pelas medidas utilizadas, visto que o ROA e o ROE representam o retorno das empresas no curto prazo, mais ligado a empresas não familiares. Anderson e Reeb (2003) aduzem que as organizações familiares possuem horizontes temporais superiores, focando em projetos de longo prazo. Seus anseios são mais complexos do que o retorno sobre o patrimônio, perpassam a credibilidade do nome da família na sociedade, perenidade no mercado, dentre outros. Este fato pode ser confirmado pela maior idade (variável de controle) média das empresas familiares na amostra. 
Tabela 2. Estatística descritiva e teste de média das variáveis.

\begin{tabular}{|c|c|c|c|c|c|c|}
\hline & \multicolumn{4}{|c|}{ Estatística descritiva } & \multirow{2}{*}{\multicolumn{2}{|c|}{ Teste de média (t de Student; bi-caudal) }} \\
\hline & \multicolumn{2}{|c|}{ Empresas familiares } & \multicolumn{2}{|c|}{ Empresas não familiares } & & \\
\hline & Média & $\mathrm{DP}$ & Média & DP & $\mathrm{T}$ & Sig. \\
\hline ROA & 0,067 & 0,060 & 0,082 & 0,063 & $-2,862$ & $0,004 *$ \\
\hline ROE & 0,078 & 0,124 & 0,101 & 0,121 & $-2,121$ & $0,034 *$ \\
\hline P\&D & 0,034 & 0,082 & 0,046 & 0,117 & $-1,329$ & 0,184 \\
\hline CAF & 0,188 & 0,187 & 0,195 & 0,196 & $-0,419$ & 0,675 \\
\hline RVCP & 0,255 & 0,210 & 0,283 & 0,169 & $-1,659$ & $0,098 * * *$ \\
\hline RVLP & 0,079 & 0,147 & 0,154 & 0,174 & $-5,326$ & $0,000^{*}$ \\
\hline TAM & 6,331 & 0,658 & 7,028 & 0,757 & $-11,259$ & $0,000 *$ \\
\hline ID & 51 & 27 & 43 & 27 & 3,400 & $0,001 *$ \\
\hline $\mathrm{FF}$ & 2,178 & 1,384 & 1,675 & 1,047 & 4,592 & $0,000 *$ \\
\hline $\mathrm{CV}$ & 0,052 & 0,135 & 0,085 & 0,145 & $-2,678$ & $0,008^{*}$ \\
\hline $\mathrm{EC}$ & 0,517 & 0,183 & 0,562 & 0,142 & $-3,088$ & $0,002 *$ \\
\hline
\end{tabular}

Nota. Legenda: $\mathrm{ROA}=$ Retorno sobre os ativos; $\mathrm{ROE}=$ Retorno sobre o patrimônio líquido; $\mathrm{P} \& \mathrm{D}=$ Pesquisa e desenvolvimento; $\mathrm{CAF}=\mathrm{Crescimento}$ do ativo fixo; $\mathrm{RVCP}$ = Remuneração variável de curto prazo; RVLP = Remuneração variável de longo prazo; TAM = Tamanho; ID = Idade; FF = Folga financeira; $\mathrm{CV}=$ Crescimento das vendas; e $\mathrm{EC}=$ Estrutura de capital.

Significância ao nível de *1\%; **5\%; ***10\%. Fonte: Dados da pesquisa.

Investimentos em P\&D e CAF são superiores em empresas não familiares, mas as diferenças não são significativas. Desta forma, infere-se que no cenário brasileiro, o nível de investimento em empresas familiares e não familiares é similar. Em literatura prévia, os resultados não são conclusivos, inclusive há ambiguidade de entendimentos. Para Yoo e Sung (2015) e Tsao et al. (2015), organizações familiares investem de forma mais intensa em P\&D, o que é condizente com sua visão de longo prazo. Todavia, em abordagens opostas, Subekti e Sumargo (2015) relatam que as organizações familiares tendem a evitar ações de risco, como é o caso de investimentos (que proporcionam resultados no longo prazo). Segundo Cheng (2014), as empresas familiares tendem a ser menos diversificadas, o que pode sinalizar investimentos inferiores. No Brasil, nenhuma das posições da literatura foi predominante.

Os resultados denotam que a prática de remunerar os executivos com valores variáveis é estatisticamente maior em empresas não familiares em comparação às empresas familiares, tanto com remuneração variável de curto prazo (significância de 10\%) quanto com de longo prazo (significância de 1\%). A Teoria da Agência postula a existência de conflitos de interesse entre acionistas e gestores, e destaca a necessidade de criação de mecanismos de controle interno a fim de alcançar o alinhamento dos interesses das partes envolvidas (Aggarwal \& Ghosh, 2015). As empresas familiares tendem a apresentar maior concentração de propriedade comparativamente às contrapartes não familiares, visto que geralmente membros da família estão envolvidos ativamente na gestão, refletindo seus anseios nas decisões das empresas (Cheng, 2014). Desta forma, é de se esperar que empresas não familiares façam uso mais extensivo de remuneração variável de curto e de longo prazo para alcançar o alinhamento de interesses das partes.

As variáveis de controle Tamanho, Crescimento das vendas e Estrutura de capital são superiores nas empresas não familiares em comparação às empresas familiares, com diferenças significativas ao nível de $1 \%$. Neste sentido, é de se esperar que com crescimento acelerado, tais empresas atinjam tamanho maior, sendo ambos os aspectos impulsionados pelas origens de recursos. O capital de terceiros (aqui identificado pela métrica de estrutura de capital), utilizado em maior intensidade por empresas não familiares, apresenta potencial de contribuir para elevação do tamanho e do crescimento das atividades. Em contrapartida, com resultado também estatisticamente significativo a $1 \%$, as empresas familiares apresentam maior média de folga financeira e idade, o que é complacente com sua aversão ao risco (maior folga para adversidades de mercado) e perpetuidade no mercado (visão de longo prazo).

\section{Modelos de regressão}

Pelas regressões, verifica-se a influência das variáveis independentes de remuneração (variável de curto prazo e de longo prazo) e de controle (tamanho, idade, folga financeira, crescimento das vendas e estrutura de capital) nas variáveis dependentes (retorno sobre os ativos, retorno sobre o patrimônio líquido, P\&D e crescimento do ativo fixo). Na Tabela 3, têm-se os modelos para posterior apreciação quanto à sua validade e às relações encontradas. 
Tabela 3. Relação da remuneração variável de curto prazo com desempenho.

\begin{tabular}{|c|c|c|c|c|c|c|}
\hline \multirow{2}{*}{ Variáveis } & \multicolumn{4}{|c|}{ ROA } & \multicolumn{2}{|c|}{ ROE } \\
\hline & Coef. & t test & Sig. & Coef. & t test & Sig. \\
\hline RVCP & 0,0434 & 2,79 & $0,005^{*}$ & 0,1091 & 3,36 & $0,001 *$ \\
\hline D_RVCP & 0,0357 & 2,24 & $0,025 * *$ & 0,0276 & 0,76 & 0,448 \\
\hline TAM & $-0,0010$ & $-0,17$ & 0,868 & 0,0019 & 0,17 & 0,864 \\
\hline ID & 0,0000 & 0,10 & 0,919 & 0,0003 & 1,40 & 0,163 \\
\hline $\mathrm{FF}$ & 0,0044 & 1,89 & $0,059 * * *$ & 0,0140 & 3,45 & $0,001^{*}$ \\
\hline $\mathrm{CV}$ & 0,1214 & 6,89 & $0,000 *$ & 0,2231 & 5,26 & $0,000 *$ \\
\hline $\mathrm{EC}$ & $-0,0036$ & $-0,18$ & 0,858 & 0,0024 & 0,05 & 0,956 \\
\hline CONS & 0,5011 & 1,35 & 0,179 & 0,0112 & 0,16 & 0,874 \\
\hline $\mathrm{R}^{2}$ & \multicolumn{4}{|c|}{0,2419} & \multicolumn{2}{|c|}{0,2347} \\
\hline Sig. Modelo & \multicolumn{4}{|c|}{$0,0000^{*}$} & \multicolumn{2}{|c|}{$0,0000^{*}$} \\
\hline Nr. Obs. & \multicolumn{4}{|c|}{522} & \multicolumn{2}{|c|}{522} \\
\hline EF de Setor & \multicolumn{4}{|c|}{ Sim } & \multicolumn{2}{|c|}{ Sim } \\
\hline EF de Ano & \multicolumn{4}{|c|}{ Sim } & \multicolumn{2}{|c|}{ Sim } \\
\hline Jarque-Bera & \multicolumn{4}{|c|}{0,0000} & \multicolumn{2}{|c|}{0,0000} \\
\hline VIF & \multicolumn{4}{|c|}{$\leq 1,94$} & \multicolumn{2}{|c|}{$\leq 1,94$} \\
\hline Durbin-Watson & \multicolumn{4}{|c|}{1,9913} & \multicolumn{2}{|c|}{1,8930} \\
\hline White Test & \multicolumn{4}{|c|}{0,0001} & \multicolumn{2}{|c|}{0,0000} \\
\hline Matriz White (por RR) & \multicolumn{4}{|c|}{ Sim } & \multicolumn{2}{|c|}{ Sim } \\
\hline
\end{tabular}

Nota. Legenda: ROA = Retorno sobre os ativos; ROE = Retorno sobre o patrimônio líquido; RVCP = Remuneração variável de curto prazo; D_RVCP = Dummy da remuneração variável de curto prazo; TAM = Tamanho; $\mathrm{ID}=$ Idade; FF = Folga financeira; $\mathrm{CV}=\mathrm{Crescimento}$ das vendas; $\mathrm{EC}=$ Estrutura de capital. $\mathrm{EF}=\mathrm{Efeito}$ fixo; VIF = Variance inflation factor; $\mathrm{RR}=$ Regressão robusta

Significância ao nível de *1\%; **5\%; $* * * 10 \%$. Fonte: Dados da pesquisa.

Conforme a Tabela 3, que mostra a relação da remuneração variável de curto prazo com o desempenho das empresas, os modelos de regressões foram significativos ao nível de $1 \%$, o que permite inferências. As variáveis explicativas (independentes e de controle), pelo $\mathrm{R}^{2}$, explicam $24,19 \%$ do ROA e $23,47 \%$ do ROE. O número de observações totaliza 522, de 87 empresas ao longo de seis períodos. Destaca-se, ainda, que foram controlados o setor corporativo e o ano da informação, a fim de eliminar quaisquer vieses desta natureza.

Quanto aos pressupostos, a normalidade foi violada em ambos os modelos mediante teste de Jarque-Bera, mas devido ao número de observações, esta foi relaxada mediante pressupostos do teorema central do limite, sendo este amplamente aceito na literatura estatística (Freund \& Simon, 2000). Na multicolinearidade (VIF), o maior fator evidenciado foi de 1,94, inferior ao fator 5 preconizado como problemático na literatura. A autocorrelação dos resíduos, por sua vez, ficou próxima ao ideal de 2 (aceitável entre 1 e 3). Em ambos os modelos houve problemas de heterocedasticidade (pelo White Test), sendo estes corrigidos com a aplicação de regressão robusta que, conforme Fávero, Belfiore, Silva e Chan (2009), insere a matriz White, ajustando os errospadrão a partir da heterocedasticidade do modelo.

Depreende-se dos resultados que o maior pagamento aos executivos via remuneração variável de curto prazo influencia positivamente no desempenho corporativo, tanto do ROA quanto do ROE (significativos ao nível de $1 \%$ ). Pela variável D_ RVCP, este efeito é maximizado para empresas não familiares, especialmente no ROA que apresentou significância ao nível de $5 \%$. As variáveis de controle apontam, em ambos os modelos, com significância entre $1 \%$ e $10 \%$, que o maior volume de folga financeira e o crescimento das vendas mais acelerado tornam o desempenho corporativo mais abundante. Por fim, tamanho, idade e estrutura de capital não influenciam nas variáveis dependentes (ROA e ROE). Vistos os resultados vinculados à remuneração variável de curto prazo, na Tabela 4 tem-se a relação da remuneração variável de longo prazo com o desempenho. 
Tabela 4. Relação da remuneração variável de longo prazo com desempenho.

\begin{tabular}{|c|c|c|c|c|c|c|}
\hline \multirow{2}{*}{ Variáveis } & \multicolumn{4}{|c|}{ ROA } & \multicolumn{2}{|c|}{ ROE } \\
\hline & Coef. & t test & Sig. & Coef. & t test & Sig. \\
\hline RVLP & 0,0236 & 0,96 & 0,337 & 0,5133 & 1,29 & 0,196 \\
\hline D_RVLP & 0,01947 & 0,72 & 0,475 & 0,0457 & 0,99 & 0,324 \\
\hline TAM & $-0,0009$ & $-0,17$ & 0,866 & $-0,0027$ & $-0,25$ & 0,804 \\
\hline ID & 0,0000 & 0,07 & 0,943 & 0,0003 & 1,18 & 0,239 \\
\hline $\mathrm{FF}$ & 0,0043 & 1,86 & $0,063 * * *$ & 0,0142 & 3,51 & $0,000 *$ \\
\hline $\mathrm{CV}$ & 0,1301 & 6,98 & $0,000 *$ & 0,2381 & 5,33 & $0,000 *$ \\
\hline $\mathrm{EC}$ & 0,0099 & 0,51 & 0,610 & 0,0394 & 0,91 & 0,362 \\
\hline CONS & 0,5542 & 1,50 & 0,133 & 0,0468 & 0,66 & 0,507 \\
\hline $\mathrm{R}^{2}$ & \multicolumn{4}{|c|}{0,2144} & \multicolumn{2}{|c|}{0,2126} \\
\hline Sig. Modelo & \multicolumn{4}{|c|}{$0,0000^{*}$} & \multicolumn{2}{|c|}{$0,0000^{*}$} \\
\hline Nr. Obs. & \multicolumn{4}{|c|}{522} & \multicolumn{2}{|c|}{522} \\
\hline EF de Setor & \multicolumn{4}{|c|}{ Sim } & \multicolumn{2}{|c|}{ Sim } \\
\hline EF de Ano & \multicolumn{4}{|c|}{ Sim } & \multicolumn{2}{|c|}{ Sim } \\
\hline Jarque-Bera & \multicolumn{4}{|c|}{0,0000} & \multicolumn{2}{|c|}{0,0000} \\
\hline VIF & \multicolumn{4}{|c|}{$\leq 2,55$} & \multicolumn{2}{|c|}{$\leq 2,55$} \\
\hline Durbin-Watson & \multicolumn{4}{|c|}{2,0195} & \multicolumn{2}{|c|}{1,8998} \\
\hline White Test & \multicolumn{4}{|c|}{0,0001} & \multicolumn{2}{|c|}{0,0000} \\
\hline Matriz White (por RR) & \multicolumn{4}{|c|}{ Sim } & \multicolumn{2}{|c|}{ Sim } \\
\hline
\end{tabular}

Nota. Legenda: ROA = Retorno sobre os ativos; ROE = Retorno sobre o patrimônio líquido; RVLP = Remuneração variável de longo prazo; D_RVLP = Dummy da remuneração variável de longo prazo; TAM = Tamanho; ID = Idade; FF = Folga financeira; CV = Crescimento das vendas; EC = Estrutura de capital. $\mathrm{EF}=$ Efeito fixo; $\mathrm{VIF}=$ Variance inflation factor; $\mathrm{RR}=$ Regressão robusta. Significância ao nível de *1\%; **5\%; ***10\%. Fonte: Dados da pesquisa.

Verifica-se na Tabela 4 que ambos os modelos são significativos ao nível de $1 \%$, suportando a validade dos achados. O poder explicativo $\left(\mathrm{R}^{2}\right)$ é de $21,44 \%$ e de $21,26 \%$ para os modelos cujas variáveis dependentes são ROA e ROE, respectivamente. O número de observações é de 522 , de 87 empresas analisadas ao longo de seis anos, sendo controlados nos modelos os efeitos fixos de setor e ano. Quanto aos pressupostos, os procedimentos são idênticos aos reportados para os modelos da Tabela 3 - ou seja, para a normalidade foram adotadas as diretrizes do teorema central do limite, os problemas de heterocedasticidade foram corrigidos por regressão robusta, e a multicolinearidade e a autocorrelação dos resíduos observadas estão de acordo com os preceitos estatísticos aceitos na literatura.

A remuneração variável de longo prazo, apesar de positiva, não apresentou significância estatística tanto em relação ao ROA quanto em relação ao ROE. Argumenta-se que o fato de as empresas despenderem mais recursos aos executivos via políticas de remuneração variável de longo prazo não maximiza o desempenho corporativo. De forma similar, a variável D_RVLP, por não apresentar significância, aponta que tal comportamento não difere entre empresas familiares e não familiares. As variáveis de controle foram significativas apenas para folga financeira e crescimento das vendas (significância variando de $1 \%$ a $10 \%$ ), com sinal positivo para o ROA e para o ROE. Logo, tamanho, idade e estrutura de capital não impactaram no desempenho corporativo das empresas. Depois dos resultados vinculados à perspectiva do desempenho, na Tabela 5 exibe-se a relação da remuneração variável de curto prazo com a política de investimentos das empresas.

Observa-se na Tabela 5 que ambos os modelos foram significativos, o que conota sua validade. O poder explicativo destes foi bastante distinto na comparação das duas variáveis dependentes, pois P\&D é explicado em $7,27 \%$ pelas variáveis independentes e CAF apresenta poder explicativo de $27,44 \%$. Ambos os modelos contêm 522 observações e foram controlados por efeitos fixos de setor e ano. Quanto ao pressuposto da normalidade, este foi relaxado conforme o teorema central do limite. Não houve problemas de multicolinearidade e de autocorrelação dos resíduos. O modelo P\&D apresentou problemas de heterocedasticidade, em que se aplicou regressão robusta para correção mediante inserção da matriz White. 
Tabela 5. Relação da remuneração variável de curto prazo com investimento.

\begin{tabular}{|c|c|c|c|c|c|c|}
\hline \multirow{2}{*}{ Variáveis } & \multicolumn{4}{|c|}{$P \& D$} & \multicolumn{2}{|c|}{ CAF } \\
\hline & Coef. & t test & Sig. & Coef. & t test & Sig. \\
\hline RVCP & 0,0132 & 0,64 & 0,525 & $-0,0890$ & $-1,93$ & $0,055^{* * *}$ \\
\hline D_RVCP & $-0,0064$ & $-0,25$ & 0,801 & 0,1751 & 3,31 & $0,001^{*}$ \\
\hline TAM & $-0,0022$ & $-0,31$ & 0,758 & $-0,0018$ & $-0,14$ & 0,892 \\
\hline ID & 0,0003 & 2,47 & $0,014^{* *}$ & $-0,0007$ & $-2,32$ & $0,020 * *$ \\
\hline $\mathrm{FF}$ & $-0,0017$ & $-0,48$ & 0,631 & 0,0180 & 2,39 & $0,017^{* *}$ \\
\hline $\mathrm{CV}$ & 0,0114 & 0,40 & 0,691 & 0,3742 & 6,71 & $0,000 *$ \\
\hline $\mathrm{EC}$ & $-0,0016$ & $-0,06$ & $-0,952$ & 0,2176 & 3,73 & $0,000^{*}$ \\
\hline CONS & 0,0335 & 0,68 & 0,496 & 0,0642 & 0,72 & 0,471 \\
\hline $\mathrm{R}^{2}$ & \multicolumn{4}{|c|}{0,0727} & \multicolumn{2}{|c|}{0,2744} \\
\hline Sig. Modelo & \multicolumn{4}{|c|}{$0,0000 *$} & \multicolumn{2}{|c|}{$0,0000^{*}$} \\
\hline Nr. Obs. & \multicolumn{4}{|c|}{522} & \multicolumn{2}{|c|}{522} \\
\hline EF de Setor & \multicolumn{4}{|c|}{ Sim } & \multicolumn{2}{|c|}{ Sim } \\
\hline EF de Ano & \multicolumn{4}{|c|}{ Sim } & \multicolumn{2}{|c|}{ Sim } \\
\hline Jarque-Bera & \multicolumn{4}{|c|}{0,0000} & \multicolumn{2}{|c|}{0,0000} \\
\hline VIF & \multicolumn{4}{|c|}{$\leq 1,94$} & \multicolumn{2}{|c|}{$\leq 1,94$} \\
\hline Durbin-Watson & \multicolumn{4}{|c|}{1,6358} & \multicolumn{2}{|c|}{1,8727} \\
\hline White Test & \multicolumn{4}{|c|}{0,0257} & \multicolumn{2}{|c|}{0,3004} \\
\hline Matriz White (por RR) & \multicolumn{4}{|c|}{ Sim } & \multicolumn{2}{|c|}{ Sim } \\
\hline
\end{tabular}

Nota. Legenda: $\mathrm{P} \& \mathrm{D}=$ Pesquisa e desenvolvimento; $\mathrm{CAF}=$ Crescimento do ativo fixo; $\mathrm{RVCP}=$ Remuneração variável de curto prazo; $\mathrm{D} \_\mathrm{RVCP}=$ Dummy da remuneração variável de curto prazo; TAM = Tamanho; ID = Idade; FF = Folga financeira; $\mathrm{CV}=\mathrm{Crescimento}$ das vendas; EC = Estrutura de capital. $\mathrm{EF}=$ Efeito fixo; VIF = Variance inflation factor; $\mathrm{RR}=$ Regressão robusta.

Significância ao nível de *1\%; **5\%; ***10\%. Fonte: Dados da pesquisa.

Para P\&D, tem-se que a variável independente de remuneração variável de curto prazo (RVCP) e sua dummy vinculada às empresas familiares não foram significativas, indicando que estas não influenciam na propensão de investimentos deste tipo em ambos os grupos de empresas. Em contrapartida, quando os investimentos são avaliados pelo CAF (crescimento dos ativos fixos), tem-se que a RVCP e a D RVCP apresentam, com significância de 10\% e $1 \%$, relação com os investimentos deste tipo, sendo que os coeficientes apresentam sinal negativo e positivo, respectivamente. Tais resultados sugerem que maior remuneração variável de curto prazo aos executivos implica redução de investimentos em ativo imobilizado. Porém, este fenômeno é revertido quando ocorre em empresas não familiares.

Nas variáveis de controle, a idade foi a única que apresentou significância (ao nível de 5\%) para P\&D e CAF (em ambas), sendo positiva e negativa, respectivamente. Todavia, por apresentar coeficiente baixo, sua influência nos investimentos corporativos é fraca. Além disso, folga financeira, crescimento das vendas e estrutura de capital, com significância entre 1\% e 5\%, estão todos relacionados positivamente ao CAF. As demais variáveis de controle (folga financeira, crescimento das vendas e estrutura de capital para o P\&D e tamanho para o P\&D e CAF) não influenciam na política de investimentos das empresas. Visto isto, na Tabela 6 demonstra-se a relação da remuneração variável de longo prazo com os investimentos.

Na Tabela 6 tem-se que os modelos são significativos, apresentando poder explicativo de $8,52 \%$ para P\&D e de $26,92 \%$ para CAF, contendo 522 observações em cada um deles. Ambas as regressões foram ainda controladas por efeitos fixos de setor e ano. Quanto aos pressupostos básicos, a normalidade foi executada pelo teorema central do limite e a heterocedasticidade presente no modelo da variável dependente CAF foi corrigida pela operacionalização de regressão robusta, que insere a matriz White. Em referência a problemas de multicolinearidade e autocorrelação, nenhum deles foi identificado. 
Tabela 6. Relação da remuneração variável de longo prazo com investimento.

\begin{tabular}{|c|c|c|c|c|c|c|}
\hline \multirow{2}{*}{ Variáveis } & \multicolumn{4}{|c|}{ P\&D } & \multicolumn{2}{|c|}{ CAF } \\
\hline & Coef. & t test & Sig. & Coef. & t test & Sig. \\
\hline RVLP & $-0,0176$ & $-0,71$ & 0,479 & 0,05596 & 0,79 & 0,431 \\
\hline D_RVLP & 0,1019 & 2,28 & $0,023 * *$ & 0,1097 & 1,40 & 0,163 \\
\hline TAM & $-0,0092$ & $-1,04$ & 0,297 & $-0,0017$ & $-0,13$ & 0,898 \\
\hline IDADE & 0,0003 & 2,31 & $0,021 * *$ & $-0,0006$ & $-1,89$ & $0,059 * * *$ \\
\hline FF & $-0,0016$ & $-0,43$ & 0,668 & 0,0160 & 2,11 & $0,035^{* * *}$ \\
\hline $\mathrm{CV}$ & 0,0117 & 0,41 & 0,686 & 0,3877 & 6,95 & $0,000 *$ \\
\hline EC & 0,0069 & 0,28 & 0,781 & 0,1882 & 3,34 & $0,001^{*}$ \\
\hline CONS & 0,0736 & 1,28 & 0,200 & 0,0669 & 0,73 & 0,463 \\
\hline $\mathrm{R}^{2}$ & \multicolumn{4}{|c|}{0,0852} & \multicolumn{2}{|c|}{0,2692} \\
\hline Sig. Modelo & \multicolumn{4}{|c|}{$0,0000^{*}$} & \multicolumn{2}{|c|}{$0,0000 *$} \\
\hline Nr. Obs. & \multicolumn{4}{|c|}{522} & \multicolumn{2}{|c|}{522} \\
\hline EF de Setor & \multicolumn{4}{|c|}{ Sim } & \multicolumn{2}{|c|}{ Sim } \\
\hline EF de Ano & \multicolumn{4}{|c|}{ Sim } & \multicolumn{2}{|c|}{ Sim } \\
\hline Jarque-Bera & \multicolumn{4}{|c|}{0,0000} & \multicolumn{2}{|c|}{0,000} \\
\hline VIF & \multicolumn{4}{|c|}{$\leq 2,55$} & \multicolumn{2}{|c|}{$\leq 2,55$} \\
\hline Durbin-Watson & \multicolumn{4}{|c|}{1,6202} & \multicolumn{2}{|c|}{1,8585} \\
\hline White Test & \multicolumn{4}{|c|}{0,0010} & \multicolumn{2}{|c|}{0,4927} \\
\hline Matriz White (por RR) & \multicolumn{4}{|c|}{ Sim } & \multicolumn{2}{|c|}{ Sim } \\
\hline
\end{tabular}

Nota. Legenda: P\&D = Pesquisa e desenvolvimento; CAF = Crescimento do ativo fixo; RVLP = Remuneração variável de longo prazo; D_RVLP = Dummy da remuneração variável de longo prazo; TAM = Tamanho; ID = Idade; FF = Folga financeira; $\mathrm{CV}=\mathrm{Crescimento}$ das vendas; EC = Estrutura de capital. $\mathrm{EF}=$ Efeito fixo; $\mathrm{VIF}=$ Variance inflation factor; $\mathrm{RR}=$ Regressão robusta.

Significância ao nível de *1\%; **5\%; ***10\%. Fonte: Dados da pesquisa.

A remuneração variável de longo prazo não apresentou significância estatística em nenhum dos dois modelos, o que indica que ela não influencia no grau de investimentos. A variável D RVLP, que visa a diferenciar empresas familiares e não familiares, foi significativa (ao nível de 5\%) apenas para P\&D, porém, por RVLP não ter apresentado significância estatística, o efeito observado entre os tipos de empresas torna-se pouco relevante. Quanto às variáveis de controle significativas (variando de $1 \%$ a $10 \%$ ), a idade apresenta relação positiva com P\&D e negativa com CAF, enquanto folga financeira, crescimento das vendas e estrutura de capital apresentam sinal positivo com CAF.

\section{Discussão dos resultados}

Os resultados desta pesquisa podem ser compreendidos por diferentes aspectos, tanto de cunho teórico quanto de cunho empírico. Neste sentido, a remuneração variável de curto prazo no desempenho corporativo revela que esta afeta positivamente o ROA e o ROE. Evidências empíricas, como de Wet (2012) na África do Sul, Alregab (2015) no Reino Unido e Subekti e Sumargo (2015) na Indonésia, sugerem que a remuneração dos executivos, dentre elas o bônus (variável de curto prazo), está positivamente associada às medidas de desempenho. Sob a perspectiva teórica, Aggarwal e Ghosh (2015) defendem a compensação dos executivos como mecanismo de alinhamento de interesses entre acionistas e gestores, sendo o ROA e o ROE duas medidas primordiais para ambas as partes.

A variável D_RVCP apresentou coeficiente positivo em ambos os modelos, apesar de significativa apenas para o ROA (ao nível de 5\%). O efeito positivo da remuneração variável de curto prazo no desempenho foi mais significativo para empresas não familiares. As empresas com gestão familiar tendem a evitar ações de risco, acarretando consequências negativas no desempenho corporativo (Subekti \& Sumargo, 2015), o que mitiga o efeito da remuneração variável. Além disso, empresas familiares possuem visão temporal superior comparativamente às não familiares, o que pode resultar em avaria dos ganhos de curto prazo (Cheng, 2014). Como o ROA e o ROE são medidas de desempenho de curto prazo, a relação entre remuneração e desempenho é maximizada para as contrapartes não familiares. Desta forma, é aceita a hipótese $H_{1 a}$, de que existe relação positiva entre a 
remuneração variável de curto prazo e o desempenho de empresas brasileiras, sendo esta diferente para empresas não familiares comparativamente a suas contrapartes familiares.

Em relação à remuneração variável de longo prazo, apesar dos coeficientes encontrados serem positivos, conforme esperado, por falta de significância estatística estes não sustentam a relação positiva entre remuneração e desempenho. Alregab (2015) argumenta que a compensação de longo prazo apresenta influência positiva no desempenho corporativo, cuja perspectiva temporal é similar. Como as medidas aqui testadas, ROA e ROE, compõem performance de curto prazo, os coeficientes não significativos encontrados devem estar atrelados ao descompasso temporal das medidas de desempenho e de remuneração utilizadas. Dito isto, rejeita-se a hipótese $\mathrm{H}_{1 \mathrm{~b}}$, de que existe relação positiva entre a remuneração variável de longo prazo dos executivos e o desempenho (de curto prazo) de empresas brasileiras, sendo esta diferente para empresas não familiares comparativamente a suas contrapartes familiares.

Quanto às políticas de investimento, foi encontrada significância na dimensão de crescimento dos ativos fixos e remuneração variável de curto prazo; já para P\&D não houve significância estatística na relação. No resultado passível de inferências (significante), tem-se que quanto maiores os pagamentos efetuados aos gestores a título de remuneração variável de curto prazo, menor tende a ser o crescimento dos ativos fixos (imobilizado). Gibbons e Murphy (1992) ressaltam que a propensão de executivos a realizar investimentos depende de inúmeros fatores, que incluem como a remuneração executiva é dimensionada.

Se parcela significativa dos pagamentos aos executivos é realizada mediante remuneração variável de curto prazo, a propensão em realizar investimentos tende a diminuir. Para Gibbons e Murphy (1992), tais decisões de investimento caracterizam negociação de despesas correntes contra receitas futuras, podendo os executivos não mais estar em seus cargos quando as receitas forem realizadas. A desarmonia entre investimentos e remuneração variável de curto prazo provoca redução na aquisição (crescimento) de ativos fixos. Todavia, pelo fato de D_RVLP ser positiva e significativa, o referido efeito é revertido para as empresas não familiares. Tal aspecto pode ser entendido mediante maior crescimento das vendas nas organizações não familiares, em que a aquisição de ativos fixos se torna necessária para suportar as novas operações, mesmo que haja descompasso temporal de interesses. Portanto, aceita-se $\mathrm{a} \mathrm{H}_{2 \mathrm{a}}$, de que existe relação negativa entre a remuneraçã̃o variável de curto prazo dos executivos e a política de investimentos de empresas brasileiras, sendo esta diferente para empresas não familiares comparativamente a suas contrapartes familiares.

No que concerne à remuneração variável de longo prazo e a política de investimentos, os resultados não foram significativos para P\&D e CAF. Para Gong (2011), os executivos, a fim de produzir efeitos superiores de suas capacidades, tendem a preferir projetos de curto prazo, que maximizem os retornos corporativos em períodos curtos, que não é o caso dos investimentos em P\&D e CAF. Por outro lado, vincular investimentos em P\&D e CAF à remuneração de longo prazo tende a proporcionar alinhamento de interesses entre acionistas e gestores, visto que a compensação executiva é um mecanismo de controle (Aggarwal \& Ghosh, 2015). No primeiro caso, os investimentos tenderiam a ser reduzidos (hipótese adotada no estudo), enquanto, no segundo caso, maximizados. No cenário brasileiro, nenhuma das duas visões se sobressaiu, não havendo, portanto, influência da RVLP nos investimentos; assim, rejeita-se a hipótese $\mathrm{H}_{2 \mathrm{~b}}$, de que existe relação negativa entre a remuneração variável de longo prazo dos executivos e a política de investimentos de empresas brasileiras, sendo esta diferente para empresas não familiares comparativamente a suas contrapartes familiares.

Em suma, os resultados desta pesquisa suportam as perspectivas da Teoria da Agência de que a remuneração variável deve ser utilizada para o alinhamento de interesses entre acionistas e gestores. Tão importante quanto o mencionado é que gestores de organizações familiares e não familiares necessitam observar as características das empresas que administram para alcançar o melhor dimensionamento estrutural. Apesar disso, é essencial ressaltar que no contexto emergente brasileiro, tais aspectos são significativos apenas para a remuneração variável de curto prazo, trazendo a perspectiva de que em nações em desenvolvimento os indivíduos pensam os processos por lacunas temporais mais estreitas. Esta última observação deve ser levada em consideração para testes futuros em países emergentes e, se consistente, elucidar novas ramificações teóricas.

\section{CONSIDERAÇÕES FINAIS}

Este estudo investigou a relação da remuneração dos executivos com o desempenho (curto prazo) e a política de investimentos (longo prazo) em empresas brasileiras familiares e não familiares listadas na bolsa de valores Brasil, Bolsa, Balcão (B3). Os resultados revelaram que a remuneração variável de curto prazo (RVPC) influencia o desempenho corporativo (ROA e ROE) e a política de investimentos das empresas (CAF), 
ao contrário da remuneração variável de longo prazo, que não apresentou relação. Isso sugere que para o alinhamento de interesses entre executivos e acionistas, a remuneração variável de curto prazo requer especial atenção nas políticas de remuneração dos executivos das empresas.

Além disso, a propriedadeeagestãocorporativa, se familiar ou não familiar, interfere na forma como estes fatores se relacionam. Para organizações não familiares, a remuneração variável de curto prazo tem maior impacto na maximização do desempenho (ROA e ROE), comparativamente às empresas familiares. Quanto à política de investimentos, a relação negativa entre a remuneração variável de curto prazo e o crescimento dos ativos fixos é revertida quando analisadas exclusivamente as empresas não familiares. Tais resultados sugerem que gestores dos diferentes tipos de organização, no que concerne à gestão e à propriedade, devem compreender as particularidades das empresas que administram a fim de alcançar os objetivos corporativos.

\section{Contribuições teóricas e práticas}

As contribuições teóricas e práticas perpassam por inúmeros fatores. A literatura prévia acerca da relação da remuneração variável no desempenho em países emergentes, como o brasileiro, é ainda incipiente. As evidências empíricas focam em nações desenvolvidas, sobretudo os Estados Unidos e países da Europa. Com o crescimento dos mercados emergentes, especialmente a Bolsa de Valores nestas nações, tornou-se viável e de interesse compreender esta nova geografia econômica mundial. Países como o Brasil apresentam características que adentram a questão com maior instabilidade econômica e política, além de uma configuração latente de empresas familiares.

A remuneração variável de curto prazo pode ser utilizada como mecanismo de alinhamento de interesses entre as partes interessadas na organização. No contexto brasileiro, este tipo de remuneração demonstrou-se como um importante instrumento de governança corporativa. Assim, a contribuição principal do estudo está vinculada à observância deste aspecto para fortalecer as organizações. Autoridades reguladoras também podem fazer uso destes resultados e sugerir regulações que visem a fortalecer as organizações listadas na Bolsa de Valores, de modo a contemplar os anseios dos investidores e atrair capital financeiro de outros mercados ao redor do mundo para o Brasil.

Destaca-se ainda a diferenciação entre empresas familiares e não familiares. O cenário brasileiro é um celeiro de empresas familiares, o que difere de algumas nações pelo mundo. Este aspecto é também confirmado para as empresas listadas na B3, visto a predominância de empresas familiares na amostra. Observou-se que existem diferenças de comportamento da remuneração variável de curto prazo quanto ao desempenho e à política de investimentos das empresas familiares e não familiares. Portanto, este estudo traz contribuições diferenciadas para a intensificação do debate acerca da temática em questão, pautando-se nas características de propriedade e gestão corporativa para uma compreensão superior do fenômeno em questão.

\section{Limitações e recomendações para pesquisas futuras}

Embora diversas dimensões tenham sido significativas, algumas medidas utilizadas apresentaram limitações quanto à sua coleta e mensuração. A variável Pesquisa e Desenvolvimento (P\&D) não foi significativa em nenhum dos modelos, o que pode estar associado à não obrigatoriedade de divulgação desta informação nos relatórios das empresas. Em aproximadamente metade das observações da amostra não constaram valores para P\&D, não sendo possível afirmar se estas empresas não fazem este tipo de investimento ou se apenas não o divulgaram em seus relatórios. Ainda que não invalide os achados, este fator é uma limitação e pode servir de amparo para que autoridades reguladoras determinem a evidenciação sobre P\&D, essencial para acionistas atuais, acionistas em potencial e outras partes interessadas.

Em face da distinção das empresas em familiares e não familiares, foram utilizados dois critérios, propriedade e/ou gestão. Quanto à propriedade, fez-se uso da métrica, conforme literatura prévia, de $20 \%$ ou mais das ações totais da companhia. Todavia, para a referida divisão foi considerada exclusivamente a propriedade de pessoas físicas nas empresas analisadas. É possível que algumas organizações sejam controladas por holdings de capital fechado que apresentam características de empresas familiares, o que possivelmente resultaria em composição também familiar da empresa enfocada na análise. Todavia, a referida limitação é mitigada quando se considera, além da propriedade, a gestão corporativa. Empresas que se constituem familiares por propriedade de pessoas jurídicas tendem a possuir membros da família na administração de sua controlada. Portanto, nesses casos, o segundo critério adotado corrige potenciais limitações de classificação. Ainda assim, podendo existir equívocos de interpretação, estes são inerentes a pesquisas deste tipo.

Como sugestões de pesquisas futuras, a inserção de outras medidas pode enriquecer a 
compreensão do fenômeno estudado. Este aspecto perpassa as variáveis de desempenho, haja vista que nesta pesquisa foram utilizadas somente medidas que refletem a performance organizacional de curto prazo, o que pode estar atrelado à falta de significância estatística para a remuneração variável de longo prazo. Assim, variáveis de desempenho de longo prazo, como medidas de mercado - market-tobook value e Q de Tobin -, podem ser adicionadas aos modelos aqui adotados, que se mostraram eficientes para o objetivo proposto. Pesquisas futuras também podem adotar como parâmetro de classificação de empresas familiares, no que tange à propriedade, apenas a composição das ações ordinárias, dado que são estas que dão direito a voto em assembleia e, portanto, representam as tomadas de decisões dos rumos estratégicos das corporações.

\section{REFERENNCIAS}

Abowd, J. M., \& Kaplan, D. S. (1999). Executive compensation: Six questions that need answering. Journal of Economic Perspectives, 13(4), 145-168. Retrieved from: https:// www.jstor.org/stable/2647017?seq=1

Aggarwal, R., \& Ghosh, A. (2015). Director's remuneration and correlation on firm's performance. International Journal of Law and Management, 57(5), 373-399. https://doi. org/10.1108/IJLMA-08-2011-0006

Alregab, H. (2015). CEO pay: The role of performance governance and political connection (Doctoral dissertation), University of Leicester, Laicester, England.

Anderson, R. C., \& Reeb, D. M. (2003). Founding-family ownership and firm performance evidence from the S\&P 500. The Journal of Finance, 58(3), 1301-1328. https://doi. org/10.1111/1540-6261.00567

Beuren, I. M., Silva, M. Z., \& Mazzioni, S. (2014). Remuneração dos executivos versus desempenho das empresas. Revista de Administração FACES Journal, 13(2), 8-25. https://doi. org/10.21714/1984-6975FACES2014V13N2ART1556

Chen, L. Y., Chen, Y. F., \& Yang, S. Y. (2017). Managerial incentives and R\&D investments: The moderating effect of the directors' and officers' liability insurance. The North American Journal of Economics and Finance, 39(1), 210222. https://doi.org/10.1016/j.najef.2016.10.007

Cheng, Q. (2014). Family firm research-A review. China Journal of Accounting Research, 7(3), 149-163. https://doi. org/10.1016/j.cjar.2014.03.002

Combs, J. G., Penney, C. R., Crook, T. R., \& Short, J. (2010). The impact of family representation on CEO compensation. Enterprise Theory and Practice, 34(6), 1125-1144. https://doi.org/10.1111/j.1540-6520.2010.00417.x
Ressalta-se a possibilidade de ainda considerar a adaptabilidade das variáveis de remuneração variável dos executivos. Nesta pesquisa adotaramse, exclusivamente, aspectos legais estabelecidos na instrução CVM n. ${ }^{\circ} 480$, de 7 de dezembro de 2009. Pesquisas futuras podem considerar o elemento informal de cada item da remuneração variável dos executivos. Por exemplo, empresas familiares podem utilizar algum tipo de remuneração para bonificar os membros da família pelo uso do nome familiar como marca da empresa. Ademais, existem discussões sobre a classificação da rubrica de pós-emprego, se esta deve incluir a remuneração variável de longo prazo. Portanto, questões específicas da remuneração variável dos executivos podem ser discutidas visando ao melhor arranjo para a compreensão do fenômeno investigado neste estudo.

Comissão de Valores Mobiliários (2009). Instrução CVM $n^{\circ} 480$, de 7 de dezembro de 2009. Retrieved from: http:// www.cvm.gov.br/legislacao/instrucoes/inst480.html

Duffhues, P., \& Kabir, R. (2008). Is the pay-performance relationship always positive? Evidence from the Netherlands. Journal of Multinational Financial Management, 18(1), 45-60. https://doi.org/10.1016/j. mulfin.2007.02.004

Eisdorfer, A., Giaccotto, C., \& White, R. (2013). Capital structure, executive compensation, and investment efficiency. Journal of Banking \& Finance, 37(2), 549-562. https:// doi.org/10.1016/j.jbankfin.2012.09.011

Fávero, L. P., Belfiore, P., Silva, F. L., \& Chan, B. L. (2009). Análise de dados: Modelagem multivariada para tomada de decisões (2nd ed.). Rio de Janeiro: Elsevier.

Flores Júnior, J. E., \& Grisci, C. L. I. (2012). Dilemas de pais e filhos no processo sucessório de empresas familiares. Revista de Administração, 47(2), 325-337. http://dx.doi. org/10.1590/S0080-21072012000200012

Freund, J. E., \& Simon, G. A. (2000). Estatística aplicada: Economia, Administração e Contabilidade (9th ed.). Porto Alegre: Bookman.

Georgen, M., \& Renneboog, L. (2011). Managerial compensation. Journal of Corporate Finance, 17(1), 1068-1077. https:// doi.org/10.1016/j.jcorpfin.2011.06.002

Gibbons, R., \& Murphy, K. J. (1992). Does executive compensation affect investment? Journal of Applied Corporate Finance, 5(2), 99-109. http://doi.org/10.3386/w4135 
Goes, T. H. M., Martins, H. H., \& Machado Filho, C. A. P. (2017). Desempenho financeiro de empresas com características familiares: Análise de empresas brasileiras listadas na BM\&F. REGE - Revista de Gestão, 24(3), 197-209. Retrieved from: http://www.revistas. usp.br/rege/article/view/134999

Gong, J. J. (2011). Examining shareholder value creation over CEO tenure: A new approach to testing effectiveness of executive compensation. Journal of Management Accounting Research, 23(1), 1-28. https://doi. org/10.2308/jmar-10105

Gregg, P., Machin, S., \& Szymanski, S. (1993). The disappearing relationship between directors' pay and corporate performance. British Journal of Industrial Relations, 31(1), 1-9. https://doi.org/10.1111/j.1467-8543.1993. tb00377.x

Jensen, M. C., \& Meckling, W. H. (1976). Theory of the firm: Managerial behavior, agency costs and ownership structure. Journal of Financial Economics, 3(4), 305360. https://doi.org/10.1016/0304-405X(76)90026-X

Kato, T., \& Kubo, K. (2006). CEO compensation and firm performance in Japan: Evidence from the new panel data on individual CEO pay. Journal of the Japanese and International Economies, 20(1), 1-19. https://doi. org/10.1016/j.jjie.2004.05.003

Kim, H., Kim, H., \& Lee, P. M. (2008). Ownership structure and the relationship between financial slack and R\&D investments: Evidence from Korean firms. Organization Science, 19(3), 404-418. https://doi.org/10.1287/ orsc. 1080.0360

Kuo, H-C., Lin, D., Lien, D., Wang, L-H., \& Yeh, L-J. (2014). Is there an inverse U-Shaped relationship between pay and performance? North American Journal of Economics and Finance, 28(1), 347-357. https://doi.org/10.1016/j. najef.2014.03.007

La Porta, R., Lopez-de-Silanes, F., \& Shleifer, A. (1999). Corporate ownership around the world. The Journal of Finance, 54(2), 471-517. https://doi.org/10.1111/00221082.00115

Lee, J. (2009). Executive perfomance-based remuneration, performance change and board structures. The International Journal of Accounting, 44(2), 138-162. https://doi.org/10.1016/j.intacc.2009.03.002

Liang, Y., Moroney, R., \& Rankin, M. (2018). Say-on-pay judgements: The two-strikes rule and the payperformance link. Accounting \& Finance, 60(Suppl. 1.). https://doi.org/10.1111/acfi.12391
Machado, D. G, \& Beuren, I. M. (2015). Política de remuneração de executivos: Um estudo em empresas industriais brasileiras, estadunidenses e inglesas. Gestão \& Regionalidade, 31(92), 4-24. https://doi.org/10.13037/ gr.vol31n92.2088

McConaughy, D. L. (2000). Family CEOs vs. nonfamily CEOs in the family-controlled firm: An examination of the level and sensitivity of pay to performance. Family Business Review, 13(2), 121-131. https://doi.org/10.1111/ j.1741-6248.2000.00121.x

Murphy, K. J. (1999). Executive compensation. In: Ashenfelter, O., \& Card, D. (Eds.). Handbook of Labor Economics (Vol. 3, Part. B, pp. 2485-2563). Holland: Elsevier.

Santos, T. R., \& Silva, J. O. (2018). A influência da família tem algum efeito? Análise da remuneração dos executivos das empresas familiares e não familiares. Revista Contabilidade e Organizações, 12(1), 1-13. https://doi. org/10.11606/issn.1982-6486.rco.2018.148149

Schmid, T., Achleitner, A. K., Ampenberger, M., \& Kaserer, C. (2014). Family firms and R\&D behavior-New evidence from a large-scale survey. Research Policy, 43(1), 233244. https://doi.org/10.1016/j.respol.2013.08.006

Silva, A., Souza, T. R., \& Klann, R. C. (2016). Tempestividade da informação contábil em empresas familiares brasileiras. Revista de Administração de Empresas, 56(5), 489-502. https://doi.org/10.1590/s0034-759020160504

Silva, A. L. C., \& Chien, A. C. Y. (2013). Remuneração executiva, valor e desempenho das empresas brasileiras listadas. Revista Brasileira de Finanças, 11(4), 481-502. http:// doi.org/10.12660/rbfin.v11n4.2013.7224

Subekti, I., \& Sumargo, D. K. (2015). Family management, executive compensation and financial performance of Indonesian listed companies. Procedia Social and Behavioral Sciences, 211(1), 578-584. https://doi. org/10.1016/j.sbspro.2015.11.076

Tsao, S. M., Lin, C. H., \& Chen, V. Y. (2015). Family ownership as a moderator between R\&D investments and CEO compensation. Journal of Business Research, 68(3), 599606. https://doi.org/10.1016/j.jbusres.2014.09.001

Wet, J. H. (2012). Executive compensation and the EVA and MVA performance of South African listed companies. Southern African Business Review, 16(3), 57-80. Retrieved from: https://www.ajol.info/index.php/ sabr/article/view/85467

Yoo, T., \& Sung, T. (2015). How outside directors facilitate corporate R\&D investment? Evidence from large Korean firms. Journal of Business Research, 68(6), 1251-1260. https://doi.org/10.1016/j.jbusres.2014.11.005 


\section{Autoria}

\section{Ilse Maria Beuren}

Rua Eng. Agronômico Andrei Cristian Ferreira, s/n, Trindade, 88040-900, Florianópolis, SC, Brasil.

E-mail: ilse.beuren@gmail.com

(1) https://orcid.org/0000-0003-4007-6408

\section{Edgar Pamplona}

Rua Antônio da Veiga, $\mathrm{n}^{\circ}$ 140, Sala D202, Itoupava Seca, 89012-903, Blumenau, SC, Brasil.

E-mail: edgarpamplona@hotmail.com

(1) https://orcid.org/0000-0002-2579-5458

\section{Maurício Leite*}

Rua Antônio da Veiga, no 140, Itoupava Seca, 89012-903, Blumenau, SC, Brasil.

E-mail: mauricio.leite@ymail.com

(1) https://orcid.org/0000-0001-7764-3969

* Autor Correspondente

\section{Financiamento}

Os autores informaram que não houve apoio financeiro para a pesquisa neste artigo.

\section{Conflito de Interesses}

Os autores informaram que não há conflito de interesses.

\section{Direitos Autorais}

A RAC detém os direitos autorais deste conteúdo.

\section{Verificação de Plágio}

A RAC mantém a prática de submeter todos os documentos aprovados para publicação à verificação de plágio, mediante o emprego de ferramentas específicas, e.g.: iThenticate.

\section{Contribuições dos Autores}

$1^{\mathbf{a}}$ autora: conceitualização (líder); curadoria de dados (apoio); análise formal (apoio); investigação (apoio); metodologia (líder); administração do projeto (líder); supervisão (líder); visualização (líder); redação- rascunho original (apoio); redação - revisão e edição (líder).

$2^{\circ}$ autor: conceitualização (igual); curadoria de dados (igual); análise formal (igual); investigação (igual); metodologia (igual); administração do projeto (igual); supervisão (igual); visualização (igual); redação - rascunho original (igual); redação - revisão e edição (igual).

3 autor: conceitualização (igual); curadoria de dados (igual); análise formal (igual); investigação (igual); metodologia (igual); administração do projeto (igual); supervisão (igual); visualização (igual); redação - rascunho original (igual); redação - revisão e edição (igual).

\section{Método de Revisão por Pares}

Este conteúdo foi avaliado utilizando o processo de revisão por pares duplo-cego (double-blind peer-review). A divulgação das informações dos pareceristas constantes na primeira página é feita somente após a conclusão do processo avaliativo, e com o consentimento voluntário dos respectivos pareceristas.

\section{Disponibilidade dos Dados}

Todos os dados e materiais foram disponibilizados publicamente por meio da plataforma Mendeley e podem ser acessados em:

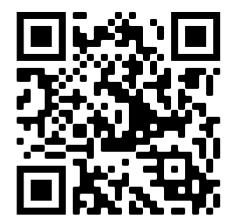

Beuren, Ilse Maria; Pamplona, Edgar; Leite, Maurício (2020), "Data for: "Executives Compensation and Performance in Family and Non-Family Brazilian Companies" published by RAC-Revista de Administração Contemporânea", Mendeley Data, v1. http://dx.doi.org/10.17632/z85vjnj9dc.1

A RAC incentiva o compartilhamento de dados mas, por observância a ditames éticos, não demanda a divulgação de qualquer meio de identificação de sujeitos de pesquisa, preservando a privacidade dos sujeitos de pesquisa. A prática de open data é viabilizar a reproducibilidade de resultados, e assegurar a irrestrita transparência dos resultados da pesquisa publicada, sem que seja demandada a identidade de sujeitos de pesquisa. . 